\title{
El rol de la Auditoría ante el lavado de activos
}

\author{
CPC Alan Errol Rozas Flores
}

Docente Asociado de la Facultad de Ciencias Contables

\section{RESUMEN}

El lavado de dinero es un fenómeno de dimensiones internacionales. Dada la interdependencia existente entre los paises y el alto desarrollo tecnológico de las telecomunicaciones, los capitales fuyen fácilmente por el sistema financiero mundial. Esto permite a la delincuencia organizada operar local e internacionalmente, por lo cual el lavado de activos normalmente involucra movimientos de capitales entre distintos paises.

El lavado de dinero generalmente involucra una serie de transacciones múltiples para ocultar la fuente de los valores financieros, para que esos valores puedan ser empleados sin comprometer a los criminales que quieren utilizar esos fondos. Esas transacciones, en general, ocurren en tres etapas: (1) Colocación, el proceso de colocar en las instituciones financieras las ganancias ilegales, mediante depósitos, transferencias con giros bancarios, u otros medios; (2) Estratificación, el proceso de separar de su origen las ganancias de las actividades criminales mediante estratos de complejas transacciones financieras; $y$ (3) integración, utilizar una transacción aparentemente legitima para ocultar las ganancias ilicitas. Con este proceso, el delincuente trata de transformar las ganancias monetarias derivadas de sus actividades ilicitas en fondos de una fuente aparentemente legal.

Dejado sin vigilancia, el lavado de dinero puede socavar la integridad de las instituciones financieras de una nación. Debido a la intensa integración de los mercados de capital, el lavado de dinero afecta adversamente a las monedas y las tasas de interés, dado que los que lavan dinero reinvierten fondos en los lugares donde sus planes tienen menos probabilidad de ser detectados, en lugar de los puntos donde las tasas de rendimiento son más elevadas. Los que lavan dinero también ejercen un impacto negativo en sus jurisdicciones al reducirse los ingresos impositivos como resultado de las economías clandestinas, al competir injustamente con las empresas legitimas, al dañar los sistemas financieros y al interrumpir el desarrollo económico. Finalmente, el dinero lavado fluye a los sistemas financieros mundiales donde puede lograr socavar las economías y las monedas nacionales.

Todo el mundo reconoce ahora que debemos enfrentar firme y efectivamente a delincuentes cada vez más escurridizos, bien financiados y tecnológicamente expertos, que están decididos a utilizar todos los medios disponibles para subvertir los sistemas financieros que son la piedra angular del comercio internacional legitimo.

El abuso continuo que cometen algunos centros financieros extraterritoriales, la proliferación de las transacciones bancarias en linea en internet y el uso generalizado de bancos y cambistas de dinero clandestinos realzan la importancia de utilizar nuevas tecnologias y estrategias enérgicas para combatir las estratagemas de lavado de dinero y estratagemas de financiamiento de terroristas. 
El combate del lavado de dinero, involucra a todos los sectores económicos. En el caso del sector financiero, su responsabilidad es mayor. El sector financiero recibe y canaliza buena parte del flujo de capitales de la economía, lo cual facilita que el dinero de procedencia ilícita se confunda con recursos de origen legal. Por lo tanto, el sector financiero es especialmente vulnerable a ser utilizado sin su consentimiento ni conocimiento para el lavado de dinero.

Por lo anterior, el sector financiero debe adoptar medidas especiales para prevenir el lavado de activos, que contribuyan a la acción de las autoridades en la prevención y castigo de este delito. Estas medidas tienen un carácter especial y superan el simple deber de colaboración con la autoridad que corresponde a todo ciudadano.

En este sentido, el tema relacionado con los mecanismos de detección y prevención del lavado de activos ha adquirido en los últimos tiempos una especial relevancia mundial. En este esfuerzo, deben participar no solo los estados y los gobiernos; sino también la sociedad, correspondiendo una responsabilidad moral, ética y profesional muy importante a la profesión contable y particularmente a los auditores.

La privilegiada posición de contadores y auditores dentro de las empresas y entidades públicas no solo les permite implementar mecanismos y controles de prevención, sino también, detectar y tomar acciones concretas frente al lavado de dinero. Sin embargo, ello requiere no solo estar actualizado y alerta sobre las características y contornos de este fenómeno, sino estar conciente de las responsabilidades que el ejercicio profesional demanda al respecto.

Palabras clave: Auditoría Externa - Auditoría Interna - Banco Pantalla - Buen criterio de la empresa Control Interno - Empresa - Manual para la Prevención del Lavado de Activos - Operaciones inusuales - Operaciones sospechosas (OS) - Personas expuestas políticamente (PEP) - Reporte de Operaciones sospechosas (ROS) - Lista OFAC.

\section{INTRODUCCIÓN}

La problemática que ocasiona el lavado de dinero se considera como un fenómeno de carácter social y económico, dado que su origen está condicionado por diversas acciones ilegales que a su vez se gestan en el desorden y la descomposición social. Esto quiere decir que el fenómeno del lavado de dinero tiene como fuentes a otros fenómenos sociales que lo alimentan y fortalecen. Su connotación económica está dada porque su accionar se desarrolla, se genera y se moviliza al interior del Sistema Financiero.

En el transcurso de los últimos diez años el lavado de dinero ha adquirido mayor envergadura, ya que no solo se limita a una circunscripción territorial determinada, pues, por lo regular, su ámbito de acción es de carácter internacional, afectando no solo intereses individuales, sino lo que es más importante, también colectivos. En su realización intervienen casi siempre organi- zaciones de índole delictiva que disimulan sus operaciones bajo aparentes actividades lícitas que pueden ser empresariales, comerciales o bancarias.

El lavado de dinero va a definirse de múltiples formas, pero siempre debe tenerse en cuenta el fin que persiguen los delincuentes, es decir, la intención de querer darle una apariencia lícita, para evitar ser vinculados con el delito de donde se obtuvo las ganancias ilegales.

En el Perú, el 26 de junio del 2002, se promulgó la Ley No 27765, Ley Penal contra el Lavado de Activos, la misma que extiende el lavado de activos a otros delitos como fuentes generadoras de ganancias ilegales. Esta norma nació como consecuencia de las disposiciones internacionales y sobretodo en aplicación de las recomendaciones del GAFI.

Pese a la nueva normativa y a los avances de la tecnología para la obtención de información, en el Perú aún no tenemos un sistema 
antilavado debidamente orgánico, cohesionado y sobre todo eficaz. Pese a la existencia de la Unidad de Inteligencia Financiera, a requerimiento de instancias internacionales y a su labor descollante en los primeros años de su existencia, aún persiste la desconexión entre los entes que luchan contra esta nueva modalidad de crimen organizado.

Instituciones como la Organización de las Naciones Unidas (ONU) y la Organización de los Estados Americanos (OEA), han promovido la adopción de normas específicas en esta materia.

El Grupo de Acción Financiera Internacional (GAFI) y la Comisión Interamericana para el Control del Abuso de Drogas, de la Organización de los Estados Americanos (CICAD - OEA), se han constituido en un apoyo fundamental en los esfuerzos de los Estados para el desarrollo de una política integral contra las diversas manifestaciones de las actividades delictivas y, especialmente, contra el lavado de dinero y/o activos.

La mayoría de los Estados miembros de la OEA han adoptado o se han comprometido a adoptar en su ordenamiento jurídico interno, las recomendaciones contenidas en el Reglamento Modelo de la CICAD-OEA. Esta adopción de recomendaciones internacionales se refleja de manera integral en las distintas áreas de la legislación interna, que de algún modo se relacionan con el lavado de dinero y/o activos.

De manera general, se puede decir que las disposiciones que regulan el sistema financiero, el sistema penal y la estructura del aparato jurisdiccional en los países latinoamericanos, con relación al tema del lavado de dinero y/o activos, se encuentran adecuadas a los estándares internacionales en la materia.

Actualmente, existe consenso en que una de las herramientas más efectivas contra el delito, es perseguir la riqueza producto de las acciones cometidas fuera de la ley; siendo, por lo tanto, la acción contra el lavado de dinero y/o activos, una de las herramientas más efectivas.

El objetivo general de este artículo es demostrar el rol actual del auditor: actualizado, responsable y efectivo frente al fenómeno del lavado de dinero

En este contexto, los objetivos específicos están constituidos por clarificar el concepto, alcance, características y etapas del fenómeno del lavado de activos, así como los avances realizados hasta la fecha en la lucha contra el lavado internacional de dinero. También es un objetivo importante mostrar de manera general el proceso de investigación que aplica la Unidad de Inteligencia Financiera del Perú y algunas técnicas y procedimientos informáticos para la prevención y detección de lavado de activos

\section{ANTECEDENTES}

Los estudiosos de este tema se remontan hasta el tiempo de los "caballeros templarios", quienes tuvieron su origen en un pequeño grupo de nueve caballeros seculares que formaron una orden después de la primera cruzada en el año de 1118. Ellos fueron el primer ejército que contaba con una estructura definida, práctica administración de recursos y estrategias. Su vestimenta se caracterizaba por un traje blanco acompañado de una cruz en el centro. Con ello, la orden llegaría a tener el respaldo de la santa sede y de las monarquías europeas en su conjunto.

El Papa Inocente II eximió a la orden de responder a las leyes del hombre y junto con la creación de distintos capítulos o sedes de la orden a través de Europa, en 180 años, los Templarios obtuvieron un poder capaz de 
desafiar a todos los tronos europeos. Durante esa época, la Iglesia prohibía los préstamos con intereses, lo cual era condenado como usura. La astucia y visión de los Templarios les habilitó el cambiar la manera en que los préstamos eran pagados y fueran capaces de evitar esta prohibición, financiando incluso a reyes. Debido a su vasta riqueza, exceso de materiales y administración, los historiadores consideran que los Templarios inventaron los servicios y sistema bancario como lo conocemos ahora.

Con el paso de los años, el concepto de lavado de dinero surge en el tiempo de las grandes mafias en Chicago y Nueva York en 1899, proveniente de una familia de inmigrantes. Al Capone solo asistió a la escuela hasta el sexto grado y ahí se une a una pandilla callejera, liderada por Jhonny Torrio e integrada por otros connotados futuros mafiosos como Lucky Luciano y Meyer Lansky, quien luego pasó a ser el cerebro financiero del grupo de Capone, y después la mente financiera escondida de las Vegas.

Por los años de 1920, Al Capone se unió a Torrio en Chicago, quien se tornó en el hombre fuerte de la familia Colosito. Los disturbios que se originaron debido a la prohibición de alcohol o Ley Volstead, crearon un campo fértil para que surgieran las "industrias criminales de mayor crecimiento": la preparación, destilación y distribución de la cerveza y licor. Torrio, apoyado por Capone, decidió hacer suyo el tema y con el objetivo de brindar la "apariencia" de hombres de negocio, desarrollaron intereses en negocios como el lavado y entintado de textiles, para de esta forma crear empresas de pantalla.

Debido a la sugerencia de Meyer Lansky, administrador del Grupo Torrio-Capone, las ganancias provenientes de las actividades ilícitas eran presentadas como parte de los ingresos del negocio de lavado de textiles y así eran declarados al Fisco de los Estados Unidos de América. Las ganancias provenientes de extorsión, tráfico de armas, alcohol y prostitución se combinaban con las de lavado de textiles y con ello logró sorprender por bastante tiempo a las autoridades norteamericanas. Es en este momento que surge el concepto de "lavado de dinero".

\section{DEFINICIÓN DE LAVADO DE ACTIVOS}

La mayoría de naciones han aceptado la definición aprobada por la Convención de las Naciones Unidas contra el Tráfico Ilícito de Estupefacientes y Sustancias Psicotrópicas de 1988; sin embargo, por ser limitante el delito precedente de tráfico ilícito de drogas, se vio la necesidad de ampliar este concepto, entendiendo que no solo el tráfico ilícito de drogas generaba grandes cantidades de dinero, sino otras formas de delitos organizados, como el tráfico de armas, tráfico de personas, corrupción, delitos aduaneros, secuestros, etc. A continuación, algunos de los conceptos más difundidos y aceptados:

- El Grupo de Acción Financiera Internacional, ha emitido esta "definición de trabajo" de lavado de dinero:

- La conversión o transferencia de propiedad, a sabiendas de que deriva de un delito criminal, con el propósito de esconder o disfrazar su procedencia ilegal o ayudar a cualquier persona involucrada en la comisión del delito a evadir las consecuencias legales de su accionar.

- Ocultar o disfrazar la naturaleza real, fuente, ubicación, disposición, movimiento, derechos con respecto a, o propiedad de, bienes a sabiendas de que derivan de ofensa criminal. 
- La adquisición, posesión o uso de bienes, sabiendo al momento en que se reciben, que deriva de una ofensa criminal o de la participación en algún delito.

- La Red de Control de Crímenes Financieros (FinCEN), por sus siglas en inglés), del Departamento del Tesoro de EE.UU. que es la principal agencia reguladora en EE.UU. sobre el lavado de dinero, define lavado de dinero como: "Disfrazar activos para ser utilizados sin que se detecte la actividad ilegal que los produjo".

- La Asociación de Especialistas Certificados en Antilavado de Dinero (ACAMS) seńala que el lavado de dinero, en general, es el proceso de esconder o disfrazar la existencia, fuente ilegal, movimiento, destino o uso ilegal de bienes o fondos producto de actividades ilegales para hacerlos aparentar legítimos. En general, involucra la ubicación de fondos en el sistema financiero, la estructuración de transacciones para disfrazar el origen, propiedad y ubicación de los fondos, y la integración de los fondos en la sociedad en la forma de bienes que tienen la apariencia de legitimidad.

- Los expertos en auditoría forense Miguel A. Cano y Danilo Lugo (Colombia) lo definen como el mecanismo a través del cual se oculta el verdadero origen de dineros provenientes de actividades ilegales, tanto en moneda nacional como extranjera y cuyo fin es vincularlos como legítimos dentro del sistema económico de un país. Estos dineros generalmente provienen de actividades ilegales como el tráfico de drogas, el secuestro, la extorsión, el boleteo, la evasión fiscal o de recursos provenientes de funcionarios corruptos tanto del sector privado como del sector público etc., los cuales pueden ser depositados o pasados por las diferentes entidades para el respectivo "lavado", tipificando conductas delictuosas contempladas por las leyes de los diferentes países.

\section{Otras definiciones:}

- Proceso mediante el cual el dinero, bienes y ganancias ilegales, pretenden legalizarse a través del sistema financiero, bursátil, comercial o por otros medios, con la finalidad de evitar su detección y decomiso.

- El lavado de activos es la forma en que el delincuente trata de asegurarse de que, al final de cuentas, el delito pague. Ello demanda que los delincuentes, bien sean narcotraficantes, delincuencia organizada, terroristas, traficantes de armas, extorsionadores o estafadores, disfracen el origen de su dinero ilegal para evitar que este sea detectado y que se les procese cuando lo utilizan. El lavado de dinero resulta esencial para lograr el funcionamiento efectivo de prácticamente toda forma de delincuencia organizada.

- El lavado de activos es la realización de actos tendientes a ocultar la naturaleza $\mathrm{u}$ origen de activos procedentes de actividades delictivas, con el fin de darles apariencia de legalidad o evitar su incautación o decomiso.

- Es el proceso a través del cual el origen de los fondos generados mediante el ejercicio de algunas actividades ilegales o criminales (tráfico de drogas o estupefacientes, contrabando de armas, corrupción, desfalco, fraude, crímenes de guante blanco, malversación pública, extorsión, trabajo ilegal y, últimamente, terrorismo) es encubierto. El objetivo de la operación, que generalmente se realiza en varios niveles, consiste en hacer que los fondos o activos 
obtenidos a través de actividades ilícitas aparezcan como el fruto de actividades legítimas y circulen sin problema en el sistema financiero.

\section{Términos sinónimos aceptables}

- Lavado de activos

- Lavado de dinero

- Blanqueo de dinero

- Legitimación de capitales

- Lavado de capitales

- Dinero negro

Denominaciones más comunes utilizadas en otros paises

- Argentina: Lavado de activos

- Bolivia: Legitimación de ganancias ilícitas

- Brasil: Lavado de bienes, derechos y valores

- Chile: Lavado de dinero

- Colombia: Lavado de activos

- Ecuador: Conversión o transformación de bienes (lavado de dinero).

- México: Operaciones con recursos de procedencia ilícita.

- Panamá: Blanqueo de capitales

- Paraguay: Lavado de dinero o bienes

- Perú: Lavado de activos

- Uruguay: Blanqueo de dinero

- Venezuela: Legitimación de capitales.

\section{CARACTERÍSTICAS DEL LAVADO DE ACTIVOS}

Considerado como un delito económico y financiero, perpetrado generalmente por delincuentes de cuello blanco que manejan cuantiosas sumas de dinero que le dan una posición económica y social privilegiada, el Lavado de activos integra un conjunto de operaciones complejas, con características, frecuencias o volúmenes que se salen de los parámetros habituales o se realizan sin un sentido económico. Trasciende a dimensiones internacionales, ya que cuenta con un avanzado desarrollo tecnológico de canales financieros a nivel mundial.

Objetivos del lavador de dinero o activos

- Preservar y dar seguridad a su fortuna

- Efectuar grandes transferencias

- Estricta confidencialidad

- Legitimar su dinero

- Formar rastros de papeles y transacciones complicadas que confundan el origen de los recursos.

\section{Perfil del lavador de dinero o activos}

Generalmente, son personas naturales o representantes de organizaciones criminales que asumen apariencia de clientes normales, muy educados e inteligentes, sociables, con apariencia de ser hombres de negocios y formados sicológicamente para vivir bajo grandes presiones.

Implicancias generales para el pais y las empresas

- El lavado de activos tiene un efecto corrosivo en la economía, el gobierno y el bienestar social de un país.

- Esta práctica distorsiona decisiones comerciales, aumenta el riesgo de quiebra de las empresas, quita al Gobierno control sobre la política económica, daña la reputación del país y expone a su pueblo al tráfico de drogas, el contrabando y otras actividades delictivas.

\section{EFECTOS PERJUDICIALES DEL LAVADO DE ACTIVOS}

Las connotaciones y efectos perjudiciales del lavado de dinero y de activos son muchos y 
muy variados. A continuación se presenta un resumen de ellos.

\section{Competencia desleal}

Uno de los efectos microeconómicos más graves del lavado de dinero es que se hace sentir en el sector privado y consiste en una competencia desleal. A menudo, quienes lo practican emplean compañías de fachada que mezclan las ganancias de actividades ilícitas con fondos legítimos, para ocultar ingresos mal habidos, subvencionando sus artículos y servicios a niveles por debajo de los precios del mercado.

\section{Debilitamiento de la integridad de los mercados financieros}

Las instituciones financieras que dependen de ganancias ilícitas tienen una tarea difícil en la administración acertada de sus bienes, obligaciones y operaciones. Dado que grandes sumas de dinero lavado pueden llegar a una institución financiera y luego desaparecer repentinamente, sin aviso, mediante transferencias electrónicas ocasionadas por factores fuera del mercado, tales como operaciones de aplicación de la ley. Pudiendo ello, originar problemas de liquidez y pánico bancario.

\section{Pérdida del control de la politica económica}

Actualmente, se calcula la magnitud del lavado de activos entre el 2 y 5 por ciento del producto interno bruto del mundo, ó aproximadamente 600.000 millones de dólares. En algunos países de mercados en desarrollo es posible que las ganancias ilícitas reduzcan los presupuestos gubernamentales, con el resultado que los gobiernos pierdan control de la política económica. De hecho, en algunos casos, la magnitud de la base acumulada de bienes de ganancias lavadas puede emplearse para acaparar el mercado o monopolizar pequeñas economías.

\section{Distorsión de la Moneda y de las Tasas de} Interés

El lavado de dinero también puede afectar adversamente las monedas y las tasas de interés cuando sus ejecutores reinvierten los fondos donde sus manejos tienen menos posibilidad de ser detectados, en lugar de hacerlo donde la tasa de rendimiento es más elevada. Por lo tanto, es una amenaza, pues genera inestabilidad monetaria debido a la distribución inadecuada de recursos ocasionada por la distorsión artificial de los precios de bienes y productos básicos.

\section{Distorsión económica e inestabilidad}

Quienes lavan activos no están interesados en generar utilidades por sus inversiones, sino en proteger sus ganancias ilícitas. Por tanto, colocan sus fondos en actividades que no necesariamente rinden beneficios económicos para el país donde están los fondos. Además, según sea el grado en que el lavado de activos y el delito financiero están presentes, desvían fondos de inversiones sólidas hacia inversiones de baja calidad, que ocultan las ganancias, afectando el crecimiento económico. En algunos países, por ejemplo, se han financiado industrias completas, como la de la construcción o la hotelera, no debido a una demanda real, sino al interés a corto plazo de los dueńos del dinero lavado. Cuando estas industrias ya no interesan, se abandonan, causando el desplome de estos sectores y un daño notable a las economías de esos países, que no pueden darse el lujo de tales pérdidas.

\section{Pérdida de rentas públicas}

El lavado de dinero disminuye los ingresos tributarios del Estado y, por tanto, perjudica indirectamente a los contribuyentes honrados. También hace más difícil la recaudación de impuestos. Esta pérdida de rentas públicas gene- 
ralmente significa tasas de impuestos más elevadas de lo que serían si las ganancias del delito, que no pagan impuestos, fueran legítimas.

\section{Riesgos para los esfuerzos de privatización}

El lavado de dinero amenaza los esfuerzos de muchos Estados para introducir reformas en sus economías mediante la privatización. Las organizaciones delictivas tienen los medios económicos para realizar mejores ofertas que la de compradores lícitos. Por ello, iniciativas de privatización económicamente beneficiosas, pueden servir de vehículo al lavado de fondos. En ocasiones anteriores, los delincuentes han podido adquirir hoteles, lugares de veraneo, casinos y bancos para ocultar ganancias ilícitas.

\section{Riesgo para la reputación de un Estado}

Los países no pueden darse el lujo de mancillar su nombre y el de sus instituciones financieras con su relación con el lavado de activos, especialmente en la economía mundial actual. La confianza en los mercados y la importante función económica que cumplen las utilidades son erosionadas por el lavado de dinero y los delitos financieros, como el lavado de ganancias ilícitas, el fraude financiero generalizado, la especulación bursátil que toma ventaja de la información interna y los desfalcos. El mal nombre a que dan lugar estas actividades disminuye las oportunidades mundiales lícitas y el crecimiento sostenible, en tanto que atrae a organizaciones delictivas internacionales con reputaciones indeseables y metas de corto plazo. El resultado puede ser la disminución del desarrollo y el crecimiento económico. Además, cuando un Estado adquiere mala reputación financiera es muy difícil superarla, requiriéndose recursos gubernamentales considerables para solucionar un problema que pudo evitarse con medidas apropiadas contra el lavado de dinero.

\section{PROCESO DEL LAVADO DE DINERO}

Los adelantos tecnológicos y la globalización, entre otros factores, han facilitado la utilización de mecanismos o tipologías de lavado, en los cuales se hace más compleja la identificación estructural de la operación o de etapas de la misma dificultando el proceso mismo de detección y comprobación de la operación de lavado.

El proceso de lavado de activos se caracteriza por manejar grandes sumas de dinero, y tiene como inconveniente su colocación, traslado y depósito. Es por ello que los delincuentes deben realizar una serie de transacciones múltiples, que generalmente ocurren en varias etapas. A continuación se presentan enfoques de distintos especialistas:

\section{Según el enfoque de la Compañía Editorial de las Publicaciones - FORTENT}

\section{Ubicación}

El objetivo es ingresar los fondos ilegales al sistema financiero sin llamar la atención de las instituciones financieras o las agencias de cumplimiento. Las técnicas de ubicación incluyen los depósitos estructurados de fondos por sumas determinadas de manera de evadir las obligaciones de reporte o la mezcla de depósitos de fondos y empresas ilegales.

\section{Ocultamiento}

Implica la movilización de fondos en todo el sistema financiero, a menudo en una compleja serie de transacciones para crear confusión y complicar el rastreo documental.

\section{Integración}

Una vez que los fondos están en el sistema financiero y aislados a través de la etapa de ocultamiento, el paso de integración es uti- 
lizado para crear la apariencia de legalidad a través de más transacciones. Estas transacciones protegen aún más al delincuente de la conexión registrada hacia los fondos brindando una explicación plausible acerca de la fuente de los fondos. Como ejemplos de estos casos puede mencionarse la compra y reventa de inmuebles, los títulos valores de inversión, fideicomisos extranjeros, u otros activos.

\section{Según el enfoque de Zund o Modelo del ciclo del agua}

\section{Precipitación}

Producción del dinero o billete originado en el delito previo.

\section{Infiltración}

El dinero recogido por la organización criminal es sometido a una primera fase de lavado transformándolo, por ejemplo en billetes de alta denominación.

\section{Corriente de aguas subterráneas}

El dinero se convierte en otras formas patrimoniales.

\section{Desagüe}

El dinero es entregado a otra área de la organización o atrás para proceder a la realización de transferencias normalmente al exterior.

\section{Nueva acumulación y estación de bombeo}

El dinero es nuevamente recibido por la organización y se destina a la apertura de cuentas en entidades financieras.

\section{Estación de depuración y aprovechamiento}

Se utilizan testaferros y se mueven los dineros de cuenta en cuenta para encubrir rastros criminales.

\section{Evaporación y precipitación}

El dinero lavado cuyo rastro legal ha sido borrado (evaporado) es destinado nuevamente a actividades criminales o utilizado para el goce del delincuente.

\section{Según el enfoque de Bernasconi o Modelo de fases}

\section{Primer Grado}

Se denomina Money Laudering, es decir, conjunto de actuaciones con las cuales en el corto plazo se liberan los bienes contaminados.

\section{Segundo Grado}

Se denomina Recycling y se refiere a las operaciones a mediano y largo plazo de bienes ya lavados que son posteriormente utilizados para lograr una desconexión absoluta del delito previo.

\section{Según el enfoque de Miguel A. Cano y Danilo Lugo (Colombia)}

1. Obtención de dinero en efectivo o medios de pago

Consecuencia de actividades ilícitas (venta de productos o prestación de servicios ilícitos).

\section{Colocación}

Incorporación del producto ilícito en el torrente financiero o no financiero de la economía local o internacional.

\section{Estratificación, diversificación o transformación}

Es cuando el dinero o los bienes introducidos en una entidad financiera o no financiera, se estructuran en sucesivas operaciones, para ocultar, invertir, transformar, asegurar o dar en custodia bienes provenientes del delito o mezclar con dineros de origen legal, con 
el propósito de disimular su origen ilícito y alejarlos de su verdadera fuente.

\section{Integración, inversión o goce de los capitales ilícitos}

El dinero ilícito regresa al sistema financiero o no financiero, disfrazado como dinero legítimo.

\section{Según el enfoque de la Unidad de Inteligencia Financiera}

\section{Colocación}

En esta fase, se recolectan los activos obtenidos ilegalmente y se introducen en la economía nacional o internacional (mediante el sistema financiero o por transacciones en efectivo), para después realizar con ellos diversas operaciones tendientes a dificultar su control, ocultar su origen y facilitar al anonimato de sus propietarios. Esta fase es la que presenta mayor riesgo para el lavador.

\section{Ocultación}

En esta fase, los activos derivados de actividades delictivas se hacen circular dentro del sistema económico del país, con el fin de cambiar su naturaleza, ubicación, origen y destino, y así perder su rastro. Fundamentalmente, se busca desvincular su origen como ingresos procedentes de actividades ilícitas.

\section{Integración}

En esta fase, trata de mezclarse el activo ilícito con una actividad económica legal para aparentar que proviene de actividades lícitas. El resultado final de esta fase es la aparición de recursos lavados en la economía, con apariencia legítima.

\section{Otros enfoques}

\section{Lavado o colocación}

Colocar las ganancias en instituciones financieras, mediante depósitos, giros cable-gráficos y otros medios.

\section{Secado o estratificación}

Distanciar de su origen las ganancias procedentes de actividades ilícitas por medio de varias capas de transacciones financieras complejas.

\section{Planchado o integración}

Es el proceso de emplear una transacción aparentemente legítima para disfrazar ganancias ilícitas.

\section{ACCIONES DE PREVENCIÓN Y DETECCIÓN DEL LAVADO DE ACTIVOS}

Por qué se debe combatir el lavado de dinero El lavado de dinero es la manera que tiene el crimen organizado para tratar de desmentir el adagio que dice que "el crimen no paga". Es un intento de decirles a los vendedores de drogas ilícitas, a los traficantes de armamento ilegal, a los funcionarios públicos corruptos y otros criminales que pueden ocultar sus ganancias, y es darles combustible para que operen y amplíen sus empresas delictivas. Combatir a los que lavan dinero y fortalecer mundialmente los regímenes legales contra el lavado de dinero reducirá los delitos financieros al negarles a los delincuentes los medios de cometer otros delitos graves. En una medida menor, pero real, fortalecer los regímenes legales contra el lavado de dinero, particularmente en las áreas de identificar a quienes originan las transferencias de giros internacionales, también tendrá impacto en 
el financiamiento del terrorismo. Como mínimo, las medidas fuertes contra el lavado de dinero significan una ayuda para crear un conjunto de pruebas para exponer la conducta delictiva y ayudar a las agencias encargadas de aplicar la ley a identificar a los perpetradores y establecer casos legales contra ellos, que conduzcan a su arresto y acusación.

Existe un variado número de iniciativas que tienen como propósito el control y la reducción del lavado de dinero. A continuación, se mencionan algunas:

\section{LAS "UNIDADES DE INTELIGENCIA FINANCIERA"}

Las Unidades de Inteligencia Financiera (UIES) son organismos nacionales que tienen distintas misiones a nivel mundial. A menudo, reúnen información sobre actividad financiera sospechosa o inusual, analizan los datos y los ponen a disposición de las autoridades y otras UIF, bajo acuerdos multilaterales de cooperación.

La creación y mantenimiento de las UIF son parte de las recomendaciones del Grupo de Acción Financiera Internacional (GAFI), y son evaluadas como parte de las revisiones que realizan el Fondo Monetario Internacional y el Banco Mundial sobre los controles de lavado de dinero y financiamiento del terrorismo de los países. (GAFI. Recomendación 26).

\section{LA UNIDAD DE INTELIGENCIA FINANCIERA (UIF) DEL PERÚ}

Creada por Ley 27693, la Unidad de Inteligencia Financiera (UIF) del Perú es una entidad de derecho público con autonomía funcional, técnica y administrativa, realiza el análisis, tratamiento y transmisión de información recibida de sujetos obligados, para la prevención y la detección del lavado de activos y el financiamiento del terrorismo.

La UIF del Perú tiene autonomía Funcional (Ejercicio independiente de sus funciones. Libre de cualquier tipo de presión o injerencia gubernamental. Tan solo interviene en aquellos casos que han sido materia de un ROS por parte de alguno de los sujetos obligados a informar, todos pertenecientes al sector privado), Técnica (Ente especializado en materia de lavado de activos), y Administrativa (Independencia en sus decisiones y actos administrativos). Sus funciones generales son:

- Recibe y analiza la información sobre transacciones sospechosas que presenten los sujetos obligados.

- Solicita la ampliación de la información recibida de los sujetos obligados respecto de un caso reportado.

- Solicita a las personas obligadas por Ley, la información relevante para la prevención y análisis del lavado de activos.

- Comunica al Ministerio Público aquellas transacciones que luego del análisis, se presuman vinculadas a actividades de lavado de activos para que proceda de acuerdo a ley.

\section{ACUERDO DE CAPITAL O BASILEA II}

El Nuevo Acuerdo de Capital o Basilea II es una serie de principios y recomendaciones del Comité de Basilea sobre supervisión bancaria, cuyo objetivo es propiciar la convergencia regulatoria hacia los estándares más eficaces y avanzados sobre medición y gestión de los principales riesgos en la industria bancaria. El Comité de Basilea forma parte del Banco Internacional de Pagos (BIS) y fue creado por acuerdo de los representantes de los Bancos Centrales de los 10 países más industrializados con el propósito de formular una serie principios y estándares de super- 
visión bancaria, los que han sido acogidos no solo por los países miembros, sino por la mayoría de países en el mundo.

En junio de 2004, se aprobó un Nuevo Acuerdo de Capital (Basilea II) para los países miembros del G-10, el mismo que empezó a regir en dichos países a partir de 2007 en sus versiones más simples, y a partir de 2008, en sus versiones más avanzadas. El objetivo principal de este Nuevo Acuerdo es lograr una mayor alineación de los requerimientos de capital de las entidades financieras con los verdaderos riesgos que estas enfrentan y, a la vez, tomar en cuenta en el esquema de supervisión la evolución de las técnicas de manejo de riesgo y la creciente complejidad y heterogeneidad del sistema financiero. Basilea II se puede definir como un marco global de supervisión bancaria, basado en tres pilares: 1) los requerimientos mínimos de capital; 2) el proceso de examen del supervisor y; 3) la disciplina de mercado.

En el Perú, la Superintendencia de Banca de Seguros es consciente de las ventajas en seguridad y estabilidad que genera un esquema como el propuesto en Basilea II, y no está al margen de esta reforma internacional de la regulación bancaria.

\section{GRUPO EGMONT}

El Grupo Egmont es una organización integrada por especialistas en investigación financiera provenientes de 63 países y 10 organizaciones internacionales.

Eduardo Amadeo, jefe de la oficina argentina de lucha contra el narcotráfico, declaró a Reuters indicó además que la globalización y apertura de los mercados abren nuevas oportunidades para el lavado de los fondos procedentes del narcotráfico, que según estimaciones de la ONU mueve alrededor de $400 \mathrm{mil}$ millones de dólares al año. Tal suma supera la facturación petrolera mundial y dobla el tamaño de la industria automotriz.

Egmont, grupo informal creado en 1995 en el Palacio Egmont, de Bruselas, Bélgica, no solo busca evitar que la internet y la globalización sean empleados para el lavado de "narcodólares", sino que sean empleados en la lucha contra tales actividades. El grupo busca, entre otras cosas, expandir el uso de internet para difundir información sobre el narcotráfico y el lavado de dinero, interconectando a la vez a los organismos de contención de tales delitos a nivel mundial.

El Grupo Egmont, es una organización multinacional que comenzó sus actividades hace 13 años y agrupa a las "Unidades de Inteligencia Financiera" nacionales encargadas de recabar la información y analizar los componentes del esfuerzo antilavado de un país, y actualmente cuenta con más de un centenar de países miembros.

\section{FELABAN (Federación Latinoamericana de Bancos)}

Frente al lavado de dinero FELABAN, ha desempeñado un importante papel en el continente latinoamericano. En efecto, la Federación Latinoamericana de Bancos suscribió, el 18 de marzo de 1996, una Declaración sobre la Prevención del Uso Indebido del Sistema Financiero en el Lavado de Activos provenientes del Narcotráfico y de otra Actividades Ilícitas, en la cual se establecieron los siguientes principios:

- Colaborar con los miembros activos de FELABAN y las autoridades gubernamentales en la formulación y adopción de normas de prevención.

- Promover el intercambio de información general, métodos y otros aspectos técnicos que puedan ser de utilidad para las asociaciones y organismos miembros. 
- Proponer a sus miembros activos que sugieran a sus afiliados la adopción de políticas de prevención de lavado de activos.

- El establecimiento de códigos de conducta, los cuales deben incluir las normas de prevención, el conocimiento de las violaciones y la aplicación de sanciones.

- El asesoramiento a los afiliados en el marco general de aplicación de las medidas.

Para efectos de desarrollar los principios atrás mencionados, FELABAN creó un Comité Latinoamericano para la Prevención y Control del Lavado de Activos, el cual fue conformado inicialmente por las asociaciones bancarias de Panamá, Colombia, Chile y Brasil.

Dicho Comité presentó en Panamá, el 30 de agosto de 1996, una Declaración, la cual contiene diversas recomendaciones para la prevención del lavado de activos. Igualmente, el Comité presentó una guía práctica para la prevención del lavado de activos, cuya base fueron las recomendaciones y acuerdos de las asociaciones bancarias latinoamericanas.

Las recomendaciones van dirigidas a la elaboración y actualización de señales de alerta que faciliten y permitan la detección de operaciones inusuales o sospechosas, la autorregulación como mecanismo fundamental en la lucha contra el lavado de activos, la colaboración y concertación con las autoridades para la expedición de normas tendientes a prevenir el lavado de activos, el desarrollo de programas de capacitación y la extensión de la aplicación de las normas de prevención a entidades no financieras.

Posteriormente, a través de los Comités correspondientes, FELEBAN ha continuado efectuando importantes esfuerzos para la difusión e implementación de mecanismos efectivos de control del lavado de activos en el sector financiero latinoamericano, desa- rrollando un papel de especial liderazgo en esta materia.

Adicionalmente, FELABAN ha hecho presencia en diferentes foros internacionales sobre este tema. Es así como ha participado en representación de la banca latinoamericana en algunas de las reuniones del GAFI.

\section{AUDITORÍA DEL LAVADO DE ACTIVOS}

La secuencia general de una Investigación por Lavado de Activos donde participa una UIF Unidad de Inteligencia Financiera (UIF) es la siguiente:

\section{Paso 1}

Se inician con un Reporte de Operación

Sospechosa (ROS)

El ROS es remitido a la UIF por el oficial de cumplimiento de cada sujeto obligado. Estos documentos se identifican con el código del sujeto obligado y oficial de cumplimiento. Deben contener los requisitos básicos para ser tratado y analizado por la UIF (Identificación del reportado e involucrados, antecedentes, descripción de la operación, motivación y documentación complementaria)

\section{¿Quien es el Oficial de Cumplimiento?}

- Es un Funcionario de nivel gerencial a dedicación exclusiva (salvo excepciones)

- Es el responsable del funcionamiento del sistema de Prevención en su institución.

- Es el enlace con la UIF- Perú y el órgano supervisor (en materia de LA/FT)

- Actúa en representación del Sujeto Obligado (SO) para efectos de la presentación del ROS.

- Cuenta con un código secreto (asignado por la UIF) para identificarse en todas sus comunicaciones dirigidas a la UIF. 
¿Qué debe entender el OC como operaciones sospechosas?

Son aquellas operaciones que por su naturaleza civil, comercial o financiera tengan una magnitud o velocidad de rotación innusual, o condiciones de complejidad que permitan presumir que proceden de alguna actividad ilícita o que no tengan un fundamento económico o lícito aparente.

\section{¿Qué son operaciones inusuales?}

Son aquellas cuya cuantía, características particulares y periodicidad no guardan relación con la actividad económica del cliente, salen de los parámetros de normalidad vigente en el mercado o no tienen un fundamento legal evidente.

¿Qué se registra en el Registro de Operaciones?

- Operaciones iguales o superiores a US\$ $10,000.00$ (o su equivalente en nuevos soles).

- Operaciones que en conjunto igualen o superen los USD 50,000.00. (o equivalente en nuevos soles) que se realicen por una persona o en su beneficio, durante un mes calendario.

- Sistema manual o informático

- Clientes habituales u ocasionales

- Operaciones superiores a US $\$ 2,500.00$ y/o US $\$ 10,000.00$ (mes) para las empresas de transferencia de fondos, casinos, casas de juego, bingos, hipódromos y loterías. (misma persona o en su beneficio).

\section{Paso 2}

La UIF elabora un informe de Inteligencia Financiera y lo remite al Ministerio Público

- El informe es el resultado de la labor realizada por la UIF y se remite al MP cuando se detectan actos que podrían estar vinculados al LA/FT.
- El informe contiene básicamente información financiera relevante pata la investigación.

- Puede contener información patrimonial, comercial, societaria, etc. vinculada al caso.

- El informe es de uso confidencial, tiene carácter de "documento de inteligencia".

- Para diseminar su contenido se requiere autorización de la UIF.

\section{Paso 3}

Con el Informe de la UIF, el Ministerio Público puede: Iniciar una Investigación Preliminar

- Fiscal (a cargo del propio Despacho).

- Policial (de inteligencia u operativa).

- Conjunta (excepcionalmente, con otra entidad).

- Formalizar una denuncia Penal ante el Juez de Turno.

Paso 4

La UIF participa también en las investigaciones mediante:

- Investigaciones conjuntas.

- Asistencia técnica.

Adicionalmente:

- Apoyo técnico mediante convenio institucional con el Ministerio Público.

- Con el objeto de contribuir a la judicialización de los casos de lavado de activos, personal de la UIF puede ser destacado a las Fiscalías Antidrogas para brindar apoyo técnico especializado.

Paso 5

El Juez Penal de Turno recibe la denuncia Fiscal

- Si el juez encuentra elementos suficientes, abre instrucción contra los denunciados.

- Dispone las medidas que estima convenientes para garantizar la recuperación o incautación de los bienes. 
- Resuelve sobre la situación jurídica de los denunciados (mandato de detención o comparecencia)

- Luego de concluido el proceso judicial (respetando el debido proceso, etc.) se establece la responsabilidad de los procesados, sanciona su conducta, ordena medidas definitivas sobre los bienes.

- En caso de no encontrar responsabilidad se absuelve a los procesados.

PROCESO DE AUDITORÍA DE LA UIF DEL PERÚ

\begin{tabular}{|l|c|c|}
\hline \multicolumn{1}{|c|}{ SUJETOS OBLIGADOS } & $\begin{array}{c}\text { Unidad de } \\
\text { Inteligencia } \\
\text { Financiera }\end{array}$ & $\begin{array}{c}\text { Ministerio } \\
\text { Publico }\end{array}$ \\
$\begin{array}{c}\text { 1. Comunicación a la UIF de operaciones sospechosas en } \\
\text { un plazo no mayor a } 30 \text { días calendario a partir de la fecha } \\
\text { en que fueron detectadas. }\end{array}$ \\
$\begin{array}{l}\text { 2. Mantener Registro de las Operaciones x importes: } \\
\geq \text { US. \$ } 10 \text { mil = día } \\
\geq \text { US. \$ } 50 \text { mil = mes }\end{array}$ \\
$\begin{array}{c}\text { Empresas que transfieren fondos efectivos, Casinos, } \\
\text { Sociedades, Lotería, Casas de juego, Bingos, Hipódromos: } \\
\geq \text { US. \$ 2.5 mil = día } \\
\geq \text { US. \$ 10 mil = mes }\end{array}$ \\
1. ROS (Reporte de Operaciones Sospechosas) \\
2. PRO (Reporte del Registro de Operaciones)
\end{tabular}

\section{TÉCNICAS Y PROCEDIMIENTOS INFORMÁTICOS PARA LA PREVENCIÓN Y DETECCIÓN DE LAVADO DE ACTIVOS}

En la actualidad, están disponibles en el mercado softwares y paquetes informáticos de auditoría muy funcionales, para la prevención y detección de lavado de activos. Estos permiten, dentro de la funcionalidad de cada sistema, entre muchas otras opciones, realizar las siguientes actividades:

\section{Verificación en listas restrictivas}

- Tanto internacionales como propias.

- En línea y fuera de ella.

- Con ingerencia en las operaciones o no.

\section{Conocimiento del cliente}

- Identificación del cliente.

- Actividades económicas.

- Características y montos de sus ingresos y egresos.

- Origen y procedencia de los fondos que va a utilizar en las negociaciones.

- Monto, frecuencia y tipo de operaciones que realiza.

- Propósito y naturaleza de la relación comercial.

Estos dos componentes permiten realizar labores de conocimiento de clientes internos y externos. La verificación de listas restrictivas es importante para evitar la posibilidad de relación con personas no deseables para el desarrollo de las actividades de la empresa. Este tipo de controles son de carácter preven- 
tivo y correctivo y permiten que la empresa se encuentre protegida frente al mercado de cara a la posibilidad de la realización de negocios en mercados internacionales y evidentemente a nivel nacional. Este control, entre otros, forma parte de la lucha mundial contra el blanqueo de capitales.

También se proveen un conjunto de herramientas que permiten el control adecuado y eficiente de la prevención de lavado de dinero, tales como:

\section{Control y alertas}

- Transacciones en efectivo.

- Transacciones múltiples en efectivo.

- Operaciones inusuales o sospechosas.

- Movimientos especiales o foráneos.

- Información financiera inconsistente.

Reportes internos

- Transacciones Inusuales.

- Operaciones sospechosas.

\section{Reportes para entidades de control}

- R.O.S

- Reporte mensual de ausencia de operaciones.

- Reporte de transacciones en efectivo.

- Reporte de clientes exonerados.

- Operaciones de divisas.

\section{Administración del riesgo LA/FT}

- Registro de eventos de riesgo por área, proceso y riesgo.

- Registro de controles sobre los riesgos.

- Registro de auditoría sobre los controles.

- Registro de tratamientos basados en la auditoría de los controles.

- Generación de mapas de riesgo por área, proceso, riesgo y factor de riesgo entre otros.

- Integración de todo tipo de empleados entorno a la administración del riesgo.
A continuación, y únicamente con fines informativos, se mencionan algunos de los tantos softwares y paquetes informáticos de auditoría que existen para la prevención y detección de Lavado de Activos.

\section{DetectART}

Control y Prevención de Lavado de Activos y Fraude (SARLAFT)

Versión: 4.6 / Año: 2007 - Desarrollo: SIDIF Ltda. (Colombia)

Producto especializado en Administración del Riesgo de Lavado de Activos y Financiación del Terrorismo (SARLAFT), y en general denominado Sistema Integral de Prevención de Lavado de Activos (SIPLA), a través del monitoreo y configuración de alertas estadísticas y de reglas de negocio. Ajustado completa y permanentemente a la normatividad. Permite administrar la información de clientes, realizar segmentación de mercado, mantener listas de bloqueados como OFAC y de clientes excluidos, permite definir reglas de negocio y de tipo estadístico para generar alarmas durante el monitoreo. Cuenta con un administrador de alertas y de flujos de gestión para definir los responsables de gestión de las mismas. Los reportes generados por la aplicación y sus herramientas gráficas permiten analizar, medir y afinar los perfiles por cliente y producto creados por el sistema, así como el comportamiento del mismo posibilitando comparaciones gráficas por diferentes conceptos. Asigna pesos de riesgo para diferentes conceptos, que permiten profundizar en medición y control del riesgo en la entidad. Aplica a las diferentes líneas de negocio dentro del Sector Financiero y Privado. Integrable con la solución RISK-O como Sistema de Administración del Riesgo Operativo (SARO) y TOPBLS como Servicios de Información 
de Listas. Brinda servicio de Monitoreo de Listas y Suministro de listas OFAC, PEPS y otras.

\section{SIPLA}

\section{Sistema de Información para la Administración del Riesgo y Prevención de Lavado de Activos y Financiación del Terrorismo}

Sistema de información diseñado exclusivamente para servir de soporte a las áreas de prevención de lavado de activos, en el manejo eficiente y dinámico de la información y de las operaciones que se debe tener en cuenta según la Federación Latinoamericana de Bancos y particularmente para cumplir con la normatividad y legislación interna de cada país, expedida por la Superintendencia de Bancos y/o de Valores, en lo referente al blanqueamiento de dinero y la Administración del Riesgo de LA/FT.

\section{SPSS - Clementine}

\section{Análisis Predictivo para Detectary Prevenir Intentos de Lavado de Activos}

Las soluciones de SPSS permiten encontrar el balance perfecto entre la implementación de defensas fuertes y efectivas contra el lavado de activos y la minimización del impacto de estas sobre el negocio. Detecta actividades financieras sospechosas, analizando la información de las transacciones realizadas. El resultado es un reporte de actividades inusuales y sospechosas. Además, mediante el modelamiento estadístico y las técnicas de inteligencia artificial, se pueden detectar anomalías de manera fácil y los falsos positivos se reducen, para estar en capacidad de tomar acciones proactivas y mejor enfocadas. Las soluciones de SPSS son fáciles de adaptar a ambientes y procesos específicos, por lo que las organizaciones usuarias tienen la se- guridad de que las regulaciones actuales y las que a futuro surgirán pueden ser adoptadas de manera eficiente y rápida.

El análisis predictivo de SPSS para la prevención y detección de fraude y lavado de activos ayuda a las entidades a detectar y prevenir actividades financieras fraudulentas, desde fraude con tarjetas de crédito hasta aquel usando cajeros automáticos, y a prevenir el lavado de activos detectando patrones sospechosos o inusuales.

\section{TOPBLS}

Servicios de Búsqueda en Listas Especiales Versión: 1.1 / Año: 2007 • Desarrollo: SIDIF Ltda. (Colombia)

Servicios de Consultas sobre Listas Públicas como OFAC, ONU, Bank of England y otras, y listas Propias TOPBLS como Funcionarios Públicos, Sector Gobierno, JetSet, Listas Judiciales nacionales como Fiscalía, Procuraduría, e internacionales como DAS, INTERPOL FBI. Estas conforman las llamadas listas PEPS, Personas Expuestas Públicamente. TOPBLS está conformada por 5 servicios complementarios: a) Consultas en el dominio www.topbls.com, b) Provee la Base de Datos PEPS, c) Programas de Consultas con el Motor TOPBLS para búsquedas inteligentes por nombre y/o ID, d) Webservice con el motor TOPBLS para ser integrado con la plataforma de negocio, y e) Servicios de suscripción para actualización diaria de listas. TOPBLS es un servicio de información nacional e internacional, con actualización DIARIA a través de monitoreo permanente sobre diversas fuentes. Integrable con diversas soluciones de Administración de Riesgos Operativo (SARO) como RISK-O, y de Prevención de Lavado de Activos y Financiación del Terrorismo (SARLAFT), como DETECTART. 


\section{AUDITORÍA DE LAVADO DE ACTIVOS EN EL SECTOR PÚBLICO}

Las Entidades Fiscalizadoras Superiores (EFS) agrupadas en la INTOSAI (Organización Internacional de Entidades Fiscalizadoras Superiores), desde el XVII INCOSAI (Congreso Internacional de Entidades Fiscalizadoras Superiores), realizada en Seúl en el año 2001, mostraron su interés por contribuir con la lucha contra el lavado internacional de dinero, y el papel que las EFS podían desempeñar en esta actividad (blanqueo internacional de capitales).

El 17 OCT 2002, en la Quincuagésima Sesión el Comité Directivo de INTOSAI acuerda crear el Grupo de Trabajo (task force) de INTOSAI "Lucha contra el lavado internacional de dinero" integrado por:

- EFS de EE.UU. (Oficina General de Cuentas - GAO), Secretaría de INTOSAI.

- EFS de Rusia (Cámara de Cuentas de la Federación Rusa)

- Una EFS por cada Grupo Regional

En febrero de 2003, el Consejo Directivo de la OLACEFS (Organización Latinoamericana y del Caribe de Entidades Fiscalizadoras Superiores) en su vigésima octava sesión ordinaria designa a la EFS de Perú, para representar a la región en el grupo especial de trabajo de la INTOSAI sobre "Lucha contra el Lavado Internacional de Dinero".

Posteriormente, en marzo de 2003, el Comité Directivo de INTOSAI asignó la Presidencia del Task Force INTOSAI sobre "Lucha contra el lavado internacional de dinero", a la EFS de Perú (Contraloría General de la República).

La misión de este grupo de trabajo consiste en promover un rol proactivo y de cooperación internacional respecto de la lucha contra el lavado de dinero, de una manera consistente con las competencias y facultades de las Entidades Fiscalizadoras Superiores y la independencia requerida de la INTOSAI. En dicho contexto, sus objetivos son:

- Promover la cooperación internacional entre las EFS y con otras organizaciones en la lucha contra el lavado de dinero.

- Identificar y compartir políticas y estrategias para su efectivo combate dentro de las competencias y facultades de las EFS.

- Diseñar y promover políticas, estrategias y acciones dentro del marco legal del lavado internacional de dinero de cada EFS, utilizando esta iniciativa para evaluar y controlar la eficiencia, efectividad, operatividad y vulnerabilidad o riesgo del sistema de lucha contra el lavado de dinero en su propio país.

Actualmente (año 2007), los países miembros son:

- EFS Perú, Presidencia

- EFS Fiji

- EFS Federación Rusa

- EFS EE.UU.

- EFS Reino Unido

- EFS Papua Nueva Guinea

- EFS Egipto

- EFS Trinidad y Tobago

- EFS Lesotho

Precisamente, en Lima, Perú, el 3 de marzo de 2005, se llevó acabo la IV Reunión del Grupo de Trabajo de INTOSAI sobre Lavado Internacional de Dinero, dicho evento fue organizado por la Contraloría General de la República de Perú, evento en el participaron las Entidades Fiscalizadoras Superiores de Estados Unidos, Fiji, Lesotho, Reino Unido, Rusia y Perú.

Excepto por la formulación de un plan de trabajo y la definición de su misión y 
objetivos, este grupo de trabajo, aún no ha definido políticas claras de lucha contra el lavado internacional de dinero en el sector público y menos aún normas y/o guías, técnicas, prácticas y procedimientos de auditoría forense aplicables para el caso.

\section{CONCLUSIONES}

1. La lucha contra el lavado de activos requiere que los actores económicos privados colaboren con el Estado, registrando las transacciones que superen determinados umbrales, identificando las transacciones sospechosas (mediante el conocimiento de sus clientes) y comunicando las mismas a las entidades pertinentes, en nuestro país a la Unidad de Inteligencia Financiera (UIF), para que esta, luego del análisis respectivo, determine si existe la presunción de la comisión del delito de lavado de activos y de resultar ello, las comunique al Ministerio Público.

2. En nuestro país la Unidad de Inteligencia Financiera (UIF) no actúa de oficio, sino frente a los Reportes de Transacciones Sospechosas que realizan los sujetos obligados a reportar.

3. La lucha contra el lavado de dinero no es una batalla en sí misma contra este mal, sino más bien contra aquellos crímenes que son la fuente del beneficio económico que busca ser puesto nuevamente en circulación bajo un manto de legalidad. Al dificultar dicha conversión se hacen menos atractivos y productivos los crímenes que lo originan.

4. Existe un variado número de iniciativas que tienen como propósito el control y la reducción del lavado de dinero. De ahí que los criminales han ido creando mecanismos y esquemas cada vez más complejos y desarrollados que utilizan para burlar los esfuerzos que se realizan para erradicar este mal. Dichos esquemas implican muchas veces la utilización de entidades ficticias, casinos, restaurantes, comercio de joyas, obras de arte, distribuidores de automóviles, operaciones de exportación e importación, etc.

5. El profesional contable tiene un espacio de preferencia y relevante en el análisis y obtención de información fidedigna de los datos de carácter financiero que normalmente se obtienen (mucha veces en forma segmentada) en la lucha contra el lavado de dinero, igualmente es de suma importancia la participación del profesional contable en la preparación del programa de detección, es decir, en los trabajos de prevención sobre información de operaciones sospechosas.

\section{REFERENCIAS}

Regulaciones

- International Moning Laudering Abetement ant Anti-terrorist Financing Act of 2001 (USA PATRIOT ACT).

\section{Guias}

- The Forty Recommendations (2003)

- Guideline Money Laudering

- Guidance Notes for Stockbrokers

- Guideline Money Laudering - Canadá

- Guidance on the Scrutiny for Transactions that may Involve the Proceeds of Foreing Official Corruption

- Eight Recomendation

- Money Laudering Model Regulations CICAD

- FAT Nine special Recommendations

\section{Convenios}

- Agreement of of Strasburg 1990 
- Agreement of Jamaica 1992

- Convention of Palermo

- UN Convention against corruption under agreements

- Acta de coordinación. UIF Perú Programa de Apoyo a la creación y desarrollo UIF's de América del Sur CICAD/BID/ OEA Mayo 2003

- Memorando de Entendimiento UIF/ UIAF Colombia. Agosto 2003
- Memorando de Entendimiento UIF/ UAF Panamá. Septiembre 2003

- Memorando de Entendimiento UIF/ Ecuador. Noviembre 2003

- Memorando de Entendimiento UIF/ Guatemala. Noviembre 2003

- Enmienda No 28 al Convenio de Narcóticos No 4, Perú y EE.UU. Enero 2004

- Memorando de Entendimiento UIF/Espańa. Febrero 2004. 